\title{
Identificação de áreas adequadas para a construção de aterros sanitários e usinas de triagem e compostagem na mesorregião da Zona da Mata, Minas Gerais
}

\author{
Identification of suitable areas for construction of landfill and waste selection \\ and composting plants in the mesoregion of Zona da Mata, Minas Gerais
}

\section{Thaís de Carvalho Felicori', Eduardo Antonio Gomes Marques², Tatiana Quintão Silva', Bárbara Batista Porto ${ }^{3}$, Tamila Caliman Bravin ${ }^{4}$, Kássia Mara Cota Santos ${ }^{5}$}

\begin{abstract}
RESUMO
A disposição final inadequada dos resíduos sólidos urbanos (RSU) em lixões é realizada em $60 \%$ dos municípios brasileiros. Ademais, a escollha das áreas para a implantação desses depósitos, comumente, não leva em consideração as restrições legais vigentes. Na Zona da Mata mineira, esse fator é agravado pela existência de extensas áreas de preservação permanente, que implica em reduzido número de áreas disponíveis para tratamento de resíduos. O consórcio intermunicipal, como forma de gestão compartilhada, é considerado uma alternativa prevista em lei para regularizar essa situação. Para nortear o consorciamento, a Fundação Estadual do Meio Ambiente (FEAM), por meio do Sistema Estadual de Meio Ambiente e Recursos Hídricos (SISEMA), subdividiu o estado em arranjos territoriais ótimos (ATOs). Considerando que as formas adequadas de tratamento de RSU mais adotadas no Brasil são aterros sanitários e usinas de triagem e compostagem, este trabalho teve como objetivo identificar áreas para a implantação de aterros sanitários e usinas de triagem e compostagem na Zona da Mata. Ademais, foi realizado o cálculo estimado das áreas requeridas para atender aos ATOs através de consórcios e o número de áreas existentes que atendessem à extensão mínima calculada. Para tanto, foi construída uma extensa base de dados para a identificação das áreas restritas legalmente e realização de análises espaciais multicritério utilizando os softwares de geoprocessamento ArcGIS e IDRISI Taiga. As análises resultaram em número reduzido de áreas passíveis de serem utilizadas para o tratamento de resíduos dificultando, assim, a utilização dos ATOs como referência para a gestão de RSU. Palavras-chave: disposição de resíduos sólidos; análise multicritério; aterro sanitário; usinas de triagem e compostagem.
\end{abstract}

\begin{abstract}
Inappropriate solid waste disposal is found in 60\% of Brazilian cities and, in most cases, site selection does not follow legal or regulatory restrictions. In the Zona da Mata region, southeast Brazil, this process is still more problematic because of the large permanent protection areas, which results in a low number of available areas for waste treatment. Considering multiple cities consortium as an alternative to ensure solid waste disposal sites in Minas Gerais state, the Minas Gerais Environmental Foundation (FEAM), using the State System of Environment and Water Resources (SISEMA), subdivided the state in optimum territorial arrangements (ATOs), which comprise units to be used in waste management shared by the cities within each ATO. Considering that the most adopted forms for appropriate solid waste treatment in Brazil are landfills and plants for sorting and composting this study aimed to determine suitable areas for landfill and plants for waste sorting and composting in the Zona da Mata region. Furthermore, site surface sizes to each ATO were calculated and the number of suitable areas for each ATO was determined. A detailed and extensive database was generated by collecting spatial information that could be used in geoprocessing softwares (ArcGIS and IDRISI Taiga) to develop spatial analysis. In general, the analysis resulted in a reduced number of suitable sites, thus making it difficult to use ATOs in shared waste management.
\end{abstract}

Keywords: solid waste disposal; multicriteria analysis; sanitary landfill; plants for waste selection and composing.

Mestre em Engenharia Civil pela Universidade Federal de Viçosa (UFV) - Viçosa (MG), Brasil.

2Doutor em Geologia pela Universidade Federal do Rio de Janeiro (UFRJ). Professor titular do Departamento de Engenharia Civil da UFV - Viçosa (MG), Brasil.

${ }^{3}$ Mestranda em Saneamento, Meio Ambiente e Recursos Hídricos pela Universidade Federal de Minas Gerais (UFMG) - Belo Horizonte (MG), Brasil.

${ }^{4}$ Engenheira Ambiental pela UFV - Viçosa (MG), Brasil.

${ }^{5}$ Engenheira Civil pela UFV - Viçosa (MG), Brasil.

Endereço para correspondência: Thaís de Carvalho Felicori - Avenida Professor Mário Werneck, 1.895, apto. 302 - Estoril - 30455-610 - Belo Horizonte (MG), Brasil-

E-mail: thaisfelicori@gmail.com

Recebido: 20/02/15 - Aceito: 26/01/16 - Reg. ABES: 146258 


\section{INTRODUÇÃO}

A disposição de resíduos sólidos urbanos (RSU) em Minas Gerais e no Brasil por muitos anos tem sido ainda realizada de forma inadequada e em áreas impróprias, nos chamados lixões - áreas escolhidas aleatoriamente, sem qualquer controle de poluição da água e do solo em seu entorno - sendo que as técnicas mais utilizadas no país e que são consideradas adequadas ambientalmente são os aterros sanitários e as usinas de triagem e compostagem.

$\mathrm{O}$ aterro sanitário consiste na disposição de resíduos em área impermeabilizada com recobrimento e compactação dos mesmos com camadas sucessivas de solo. $\mathrm{O}$ tratamento dos resíduos ocorre por meio de digestão anaeróbia e requer um controle ambiental dos líquidos lixiviados (chorume) e do biogás resultantes do processo. Esses líquidos são coletados por meio de drenos e tratados em lagoas aeróbias e o biogás é queimado ou pode ser coletado para reaproveitamento e geração de energia.

Enquanto o aterro sanitário é uma técnica de disposição final, a unidade de triagem e compostagem (UTC) é uma técnica que deve preceder a etapa de disposição, uma vez que proporciona o reaproveitamento dos resíduos por meio da triagem dos materiais recicláveis e da compostagem da porção orgânica para geração de adubo orgânico.

Os custos envolvidos na implantação e operação de tais equipamentos públicos são elevados e muitos municípios têm dificuldades em regularizar a gestão de resíduos, devido a limitações financeiras e técnicas. Para estimular a solução dessa problemática, a Política Nacional de Resíduos Sólidos (PNRS) (BRASIL, 2010) propôs o incentivo à adoção de consórcios intermunicipais. Esses consórcios visam dividir esses custos entre as administrações públicas e facilitar a obtenção de recursos para a sua implantação.

Para tanto, em âmbito estadual, o Sistema Estadual de Meio Ambiente e Recursos Hídricos (Sisema) propôs a divisão do estado de Minas Gerais em arranjos territoriais ótimos (ATOs) para a gestão integrada de resíduos sólidos urbanos.

Nesse contexto, este estudo teve como objetivo a identificação das áreas disponíveis para a construção de sistemas de disposição de resíduos na Zona da Mata de Minas Gerais com base nas diversas restrições legais vigentes e critérios socioeconômicos, utilizando ferramentas de sistemas de informação geográficas (SIG) e análise multicritério. Além disso, este estudo visou analisar a viabilidade da criação dos consórcios intermunicipais, a partir da delimitação dos ATOs, pela identificação quantitativa e qualitativa das áreas necessárias para atender a cada ATO.

Foram utilizados como parâmetros de restrição os critérios estabelecidos pelo Código Florestal Brasileiro para delimitação de áreas de preservação permanente; pela Deliberação Normativa do Conselho de Política Ambiental (COPAM) no 118 (COPAM, 2008), que estabelece diretrizes para adequação da disposição final dos RSUs e define parâmetros para escolha da área a ser utilizada para a disposição adequada de RSUs; e, finalmente, pela Portaria n 249 (BRASIL, 2011) do Ministério da Defesa, que dispõe sobre o Plano Básico de Gerenciamento do Risco Aviário (PBGRA), e define a área de gerenciamento de risco aviário, área restrita para a construção de depósitos de resíduos sólidos. Além disso, foram identificadas as unidades de proteção integral e as unidades de uso sustentável determinadas para a mesorregião, de acordo com a Lei no 9.985 (BRASIL, 2000), que institui o Sistema Nacional de Unidades de Conservação da Natureza.

\section{Caracterização da área de estudo}

A mesorregião da Zona da Mata está situada na porção sudeste do estado de Minas Gerais (Figura 1) e é formada por 7 microrregiões (Juiz de Fora, Cataguases, Ubá, Viçosa, Ponte Nova, Manhuaçu e Muriaé), constituídas por 142 municípios, que ocupam uma área total de $35.726 \mathrm{~km}^{2}$ (6,1\% da área total do estado de Minas Gerais). A população é estimada em 2.145.945 habitantes (IBGE, 2012a).

Segundo a delimitação dos ATOs, a Zona da Mata mineira abrange dez ATOs, dos quais quatro encontram-se inteiramente inseridos no limite político da mesorregião, enquanto os demais possuem pequena ou grande porção de sua área inserida na Zona da Mata, como se observa na Figura 2. Na Tabela 1 têm-se os ATOs e as respectivas cidades sede que compõem a mesorregião da Zona da Mata.

\section{METODOLOGIA}

A pesquisa foi desenvolvida a partir da realização das seguintes etapas:

- levantamento dos dados necessários para a análise, junto a órgãos públicos, laboratórios de análises espaciais, docentes e discentes;

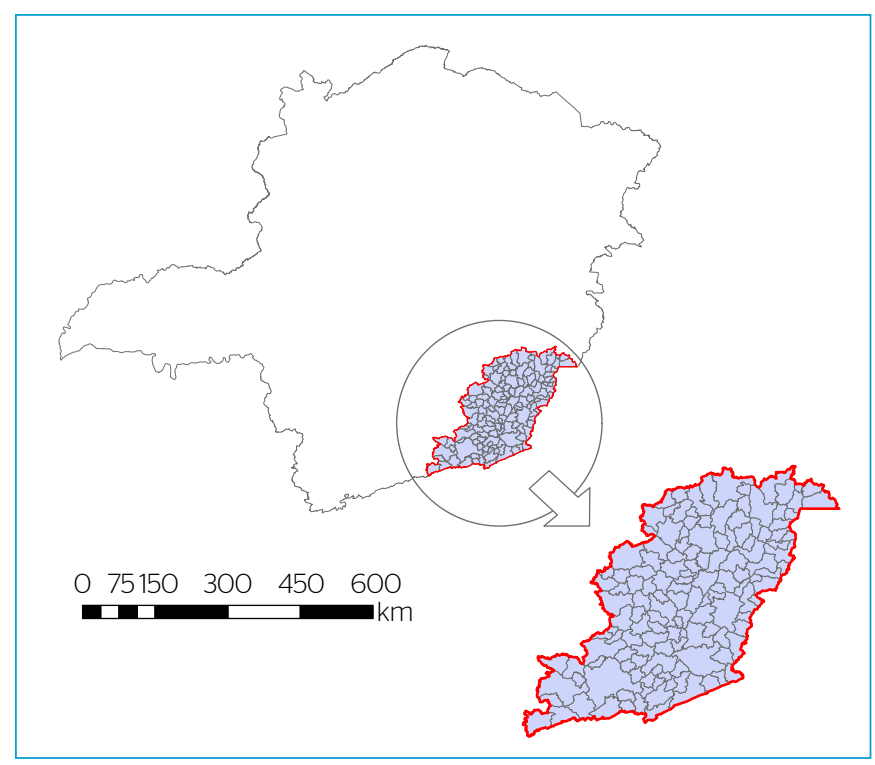

Figura 1 - Localização da zona da mata no estado de Minas Gerais. 
- edição e adequação dos dados para o processamento na análise espacial;

- elaboração de planos de informação de restrição;

- análise espacial nos softwares ArcGIS 10.0 e IDRISI Taiga; e

- identificação das áreas e análise dos resultados obtidos.

\section{Análise multicritério}

De um modo geral, os processos de decisão pretendem satisfazer objetivos e são desenvolvidos com base na avaliação de vários critérios. Trata-se, essencialmente, de um processo de decisão de natureza "multicritério", no qual diversos atributos do problema são considerados na avaliação.

Os critérios podem ser classificados em restrições ou fatores. As restrições são determinadas de acordo com a lógica booleana (valores de 1 ou 0 que representam, respectivamente, sim ou não) para identificar as áreas aptas e remover as áreas inaptas da análise. Os fatores, por outro lado, são de natureza contínua e representam uma variação de aptidão; qualificando as áreas de acordo com as características relevantes ao estudo.

A combinação desses critérios, de acordo com as metodologias descritas a seguir, auxilia no processo de decisão, que consiste na avaliação das áreas com maior adequabilidade para o uso em estudo, dentro de um determinado espaço geográfico.

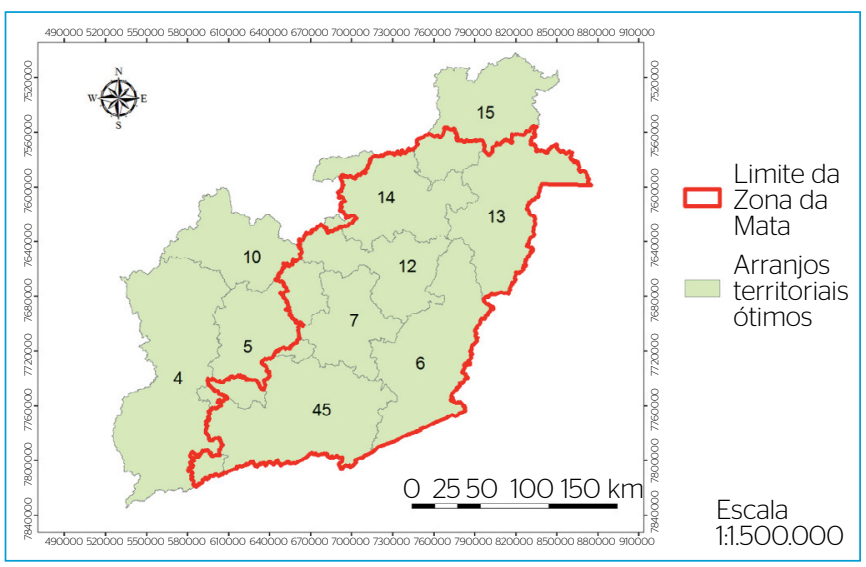

Figura 2 - Arranjos territoriais ótimos referentes à Zona da Mata.

Tabela 1 - Arranjos territoriais ótimos que compõem a Zona da Mata.

\begin{tabular}{c|c} 
ATO & Cidade sede \\
\hline 4 & São João Del-Rei \\
\hline 5 & Barbacena \\
\hline 6 & Cataguases \\
\hline 7 & Ubá \\
\hline 10 & Conselheiro Lafaiete \\
\hline 12 & Viçosa \\
\hline 13 & Manhuaçu \\
\hline 14 & Ponte Nova \\
\hline 15 & Caratinga \\
\hline 45 & Juiz de Fora \\
\hline
\end{tabular}

ATO: arranjo territorial ótimo.

Fonte: FEAM (2O14)
A realização do estudo consiste, resumidamente, em um extenso processo de coleta e manipulação de dados utilizando o software ArcGIS 10.0 para serem processados posteriormente em análise multicritério em um segundo software, IDRISI Taiga. A descrição das etapas requeridas no desenvolvimento do estudo é detalhada a seguir.

\section{Levantamento da base de dados}

A principal fonte de dados georreferenciados deste trabalho foram as cartas topográficas vetoriais do mapeamento sistemático do Instituto Brasileiro de Geografia e Estatística (IBGE), contendo:

- hidrografia;

- hipsografia;

- localidades;

- sistema viário;

- limites;

- obras e edificações;

- pontos de referência; e

- vegetação.

A região da Zona da Mata abrange 3 cartas na escala 1:100.000 e 67 cartas na escala 1:50.000 (IBGE, 2012b). As cartas não disponíveis pelo IBGE foram obtidas junto ao Instituto de Geociências Aplicadas (IGA/MG). O modelo digital de elevação utilizado foi fornecido pelo Laboratório de Geoprocessamento da Universidade Federal de Viçosa (LABGEO-UFV) e é proveniente do sensor ASTER com resolução espacial de 30 metros.

Também foram fornecidas pelo LABGEO-UFV as áreas de preservação permanente (APPs) de topo de morro da Zona da Mata, obtidas por meio de funções matemáticas no software para sistema de informações geográficas (SIG) ArcGIS10, de acordo com a metodologia desenvolvida por Oliveira e Fernandes Filho (2013), para atender às novas restrições do Novo Código Florestal Brasileiro.

As unidades de conservação foram obtidas por meio do Cadastro Nacional de Unidades de Conservação, que corresponde a um sistema integrado de banco de dados, mantido pelo Ministério do Meio Ambiente, com informações oficiais sobre as unidades de conservação.

\section{Obtenção da imagem de satélite}

A imagem utilizada no estudo foi fornecida pelo IGA/MG, e foi obtida pelo satélite RapidEYE, no ano de 2010. A imagem possui resolução espacial de 5 metros.

\section{Padronização do sistema de referência horizontal (datum) das cartas}

As cartas obtidas pelo IBGE e IGA apresentam diferenças quanto ao sistema de referência horizontal (Datum) padrão de cada uma. Algumas cartas apresentam o Sistema Geodésico de Referência Horizontal SAD69 
e outras o Sistema Córrego Alegre. Para compatibilizá-las em uma base cartográfica contínua, foram feitas transformações para o Datum oficial do Brasil, SIRGAS 2000. As transformações foram realizadas utilizando o software da ESRI ArcGIS ${ }^{\oplus}$ versão 10.0, tanto para as cartas do IBGE quanto para as cartas do IGA. O sistema de projeção adotado foi o Universal Transversa de Mercator (UTM).

\section{Delimitação das áreas urbanas e núcleos populacionais}

Para a delimitação das áreas urbanas foi utilizada a técnica de classificação supervisionada de imagens usando o algoritmo da máxima verossimilhança no software ArcGIS ${ }^{\circledR}$ 10.0. Em seguida, as vilas e comunidades não demarcadas pelo algoritmo foram delimitadas manualmente pela criação de polígonos por análise das imagens RapidEYE e das imagens de satélite fornecidas pelo software Google Earth.

\section{Obtenção do Modelo Digital de Elevação Hidrologicamente Consistente}

O Modelo Digital de Elevação Hidrologicamente Consistente (MDEHC) foi gerado com o intuito de obter um modelo de elevação condizente com a realidade e de acordo com a hidrografia do IBGE.

\section{Análise estratégica de decisão: estabelecimento de critérios}

\section{Critérios restritivos (áreas de restrição)}

Os planos de informação correspondentes às áreas de restrição foram obtidos de acordo com a lógica booleana, na qual as áreas inaptas para o objetivo do estudo foram classificadas com o valor 0 e as áreas aptas receberam a valoração 1, de acordo com as normas legais relevantes para a escolha de áreas a serem utilizadas para a disposição de resíduos sólidos urbanos, conforme a Tabela 2.

As unidades de conservação (UCs) são espaços territoriais que possuem restrições quanto ao uso. Com isso, essas áreas se tornam inviáveis para a implantação de aterros sanitários. As UCs inseridas na mesorregião da Zona da Mata estão apresentadas na Figura 3 foram identificadas e estão descritas na Tabela 3.

\section{Critérios escalonados (fatores)}

Os fatores são critérios utilizados de acordo com a aptidão com o uso desejado, no caso, áreas adequadas para a disposição de resíduos. Para tanto, os diferentes fatores foram classificados de acordo com a lógica fuzzy, através da qual são obtidos planos de informação de adequabilidade padronizados com valores de 0 (adequabilidade mínima) a 255 (adequabilidade máxima).

Essa padronização é obtida a partir da aplicação de funções de pertinência fuzzy para a definição de uma superfície de aptidão para os diferentes critérios (WEBER \& HASENACK, 2000). As funções mais comumente usadas são: sigmoidal, linear, J-shaped e complexa (ZADEH, 1965). Neste trabalho foram utilizadas as funções linear e sigmoidal.

Para a escolha dos fatores utilizou-se como referência as restrições presentes na DN COPAM n $118 / 2008$, referências bibliográficas e os impactos socioambientais negativos causados, muitas vezes, pela utilização de áreas impróprias ou selecionadas sem critério para receberem os RSUs, bem como as principais dificuldades enfrentadas pelas administrações municipais.

Os fatores, as funções aplicadas a cada um deles, bem como seus respectivos pontos de controle, estão listados na Tabela 4.

\section{Fator distância de cursos d'água}

Considerando o elevado teor impactante da disposição de resíduos sólidos sobre os cursos d'água, devido à possibilidade de contaminação dos rios por escoamento superficial ou do lençol freático por infiltração de chorume no solo, além da distância mínima de $300 \mathrm{~m}$ estabelecida pela norma, considerou-se, ainda, um aumento da aptidão com o aumento da distância da hidrografia utilizando-se, para isso, a função fuzzy sigmoidal crescente. Os valores máximos de aptidão para esse fator são atingidos a partir da distância de $700 \mathrm{~m}$.

\section{Fator distância de estradas vicinais}

A DN COPAM no 118/2008 determina que o acesso para a área de disposição de resíduos deve ser adequado para que o transporte dos mesmos e a operação do aterro sejam funcionais. Nesse caso, esse fator visa estabelecer uma elevada aptidão para as áreas mais próximas das estradas vicinais, a partir da distância mínima de 100 m estabelecida pela legislação citada. A padronização desse fator foi gerada então pela função fuzzy linear decrescente.

Tabela 2 - Restrições legais para a escolha de áreas para a disposição de resíduos sólidos urbanos.

\begin{tabular}{c|c|c} 
ID & Restrição & Norma mais restritiva \\
R1 & $\begin{array}{c}\text { Distância mínima de } \\
300 \text { m de cursos d’água }\end{array}$ & DN COPAM no 118/2008 \\
\hline R2 & $\begin{array}{c}\text { Distância mínima de } \\
100 \text { m do sistema viário }\end{array}$ & DN COPAM no 118/2008 \\
\hline R3 & Declividade inferior a 30\% & DN COPAM no 118/2008 \\
\hline R4 & $\begin{array}{c}\text { Distância mínima de } 500 \text { m de } \\
\text { núcleos populacionais }\end{array}$ & DN COPAM no 118/2008 \\
\hline R5 & APPs de topo de morro & Lei no 12.651/2012 \\
\hline R6 & Distância de 9 km de aeroportos & $\begin{array}{c}\text { Portaria n० 249/GCS/2011 do } \\
\text { Ministério da Defesa }\end{array}$ \\
\hline R7 & Unidades de conservação & Lei no 9.985/2000 \\
\hline R8 & Limite ATO & \\
\hline
\end{tabular}

APP: área de proteção permanente; DN COPAM: Deliberação Normativa do Conselho de Políticas Ambientais de Minas Gerais; ATO: arranjo territorial ótimo.

Fonte: COPAM (2008), BRASIL (2012), BRASIL (2011), BRASIL (2000). 


\section{Fator distância de estradas principais}

A partir da distância mínima de $100 \mathrm{~m}$, tem-se, nesse caso, uma elevada aptidão à medida que se distancia das estradas principais, uma vez que a proximidade excessiva pode prejudicar o tráfego de veículos devido à possível presença de resíduos mais leves como sacolas plásticas. Assim, utilizou-se a função fuzzy sigmoidal simétrica para se obter as maiores aptidões entre as distâncias de 1.000 e $4.000 \mathrm{~m}$. A redução da aptidão ocorre a partir de $4.000 \mathrm{~m}$, uma vez que a presença de rodovias principais na rota de acesso entre o depósito e o município aumenta a eficiência do transporte de resíduos.

\section{Fator declividade}

Considerando a declividade máxima de $30 \%$, permitida pela legislação, têm-se os valores mais elevados de aptidão entre as declividades de 5 e $25 \%$, já que alguma declividade pode indicar a presença de material de empréstimo e facilitar a construção das trincheiras, quando for o caso. Para esse fator foi utilizada a função fuzzy linear simétrica para padronização dos dados de declividade em escala de aptidão, com os pontos de controle cita$\operatorname{dos}(0,5,25$ e $30 \%)$.

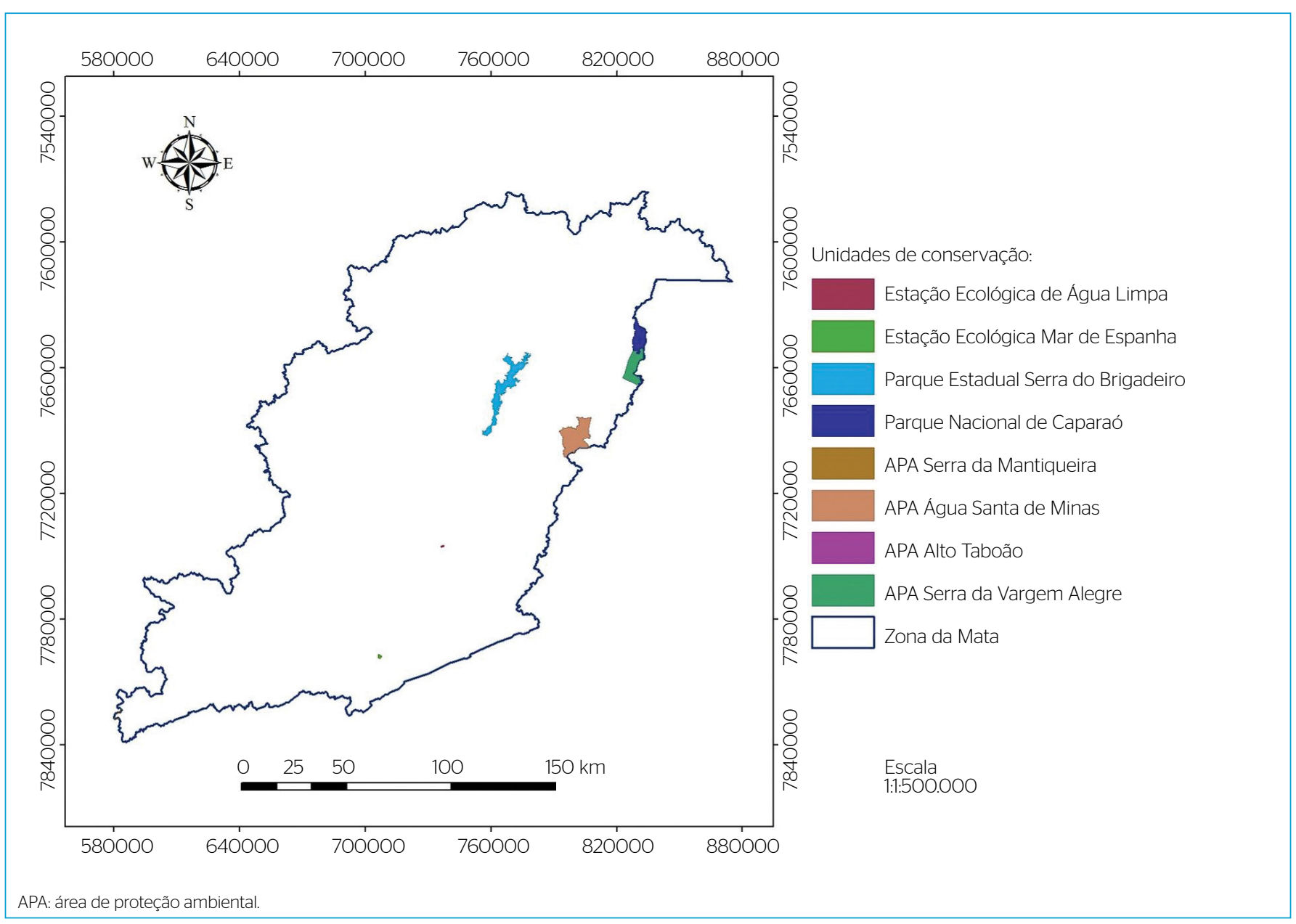

Figura 3 - Unidades de conservação inseridas na Zona da Mata mineira.

Tabela 3 - Unidades de conservação inseridas na Zona da Mata mineira.

\begin{tabular}{c|c|c|c} 
ID & Nome da Unidade de Conservação & Categoria & Grupo \\
\hline 1 & Área de Proteção Ambiental Água Santa de Minas & Área de Preservação Ambiental & Uso Sustentável \\
\hline 2 & Area de Proteção Ambiental Alto Taboão & Área de Preservação Ambiental & Uso Sustentável \\
\hline 3 & Area de Proteção Ambiental Serra da Mantiqueira & Área de Preservação Ambiental & Uso Sustentável \\
\hline 4 & Area de Proteção Ambiental Serra da Vargem Alegre & Área de Preservação Ambiental & Proteção Integral \\
\hline 5 & Estação Ecológica de Água Limpa & Estação Ecológica & Proteção Integral \\
\hline 6 & Estação Ecológica Mar de Espanha & Estação Ecológica & Proteção Integral \\
\hline 7 & Parque Estadual Serra do Brigadeiro & Parque & Proteção Integral \\
\hline 8 & Parque Nacional do Caparaó & Parque & Proteção Integral \\
\hline
\end{tabular}

Fonte: Cadastro de unidades de conservação (BRASIL, 2014). 


\section{Fator distância de núcleo populacional urbano}

Para os núcleos urbanos, considerou-se um aumento da adequabilidade das áreas à medida que se distancia das cidades no intervalo de $500 \mathrm{a}$ $2.000 \mathrm{~m}$, utilizando a função fuzzy linear simétrica. No intervalo de 2 a $8 \mathrm{~km}$ foi atribuído o valor de adequabilidade máxima e, a partir de $8 \mathrm{~km}$, a aptidão decresce, uma vez que os custos com transporte ficam elevados. Nesse caso, os valores mínimos de aptidão são observados para distâncias inferiores a $500 \mathrm{~m}$ e superiores a $10 \mathrm{~km}$ e máximos entre as distâncias de 2 a $8 \mathrm{~km}$.

\section{Fator distância de núcleo populacional rural}

Nesse caso, as maiores aptidões foram consideradas para as áreas mais distantes dos núcleos populacionais rurais. Afinal, a proximidade prejudica as atividades rurais e não favorece o transporte, uma vez que o volume de resíduos na zona rural é reduzido. Sendo assim, para esse fator considerou-se a função fuzzy linear crescente com valores máximos de adequabilidade, obtidos a partir de $700 \mathrm{~m}$.

As variáveis apresentam importâncias relativas para a escolha da área. Portanto, para a determinação de pesos diferentes para cada fator, as condicionantes foram comparadas duas a duas para se obter um peso final para cada variável. Essa comparação foi realizada por meio do método analytical hierarchy process (AHP - processo de hierarquização analítica) proposto por Saaty (1990), e executado por meio da matriz WEIGHT do software IDRISI TAIGA.

A análise AHP foi utilizada para multiplicar os planos de informação, padronizados pelo módulo FUZZY (escala 0-255), pelo seu peso obtido na matriz WEIGHT (Tabela 5). A consistência dos pesos é verificada através do índice de consistência (IC), calculado pelo software e que, segundo Saaty (1990), deve apresentar valor inferior a 0,1. Nesse caso, obteve-se IC igual a 0,05 indicando a consistência da matriz.
Neste trabalho utilizou-se o método da combinação linear ponderada (WLC), conforme Voogd (1983), para a integração dos fatores após a padronização dos mesmos a uma escala contínua pela lógica Fuzzy.

\section{Estimativa das áreas de disposição de resíduos sólidos urbanos para cada arranjo territorial ótimo}

A estimativa do valor de área para os diferentes ATOs foi feita com base no cálculo do volume total de resíduos gerados em um período de 20 anos, reduzido da porção de materiais recicláveis e da matéria orgânica a serem triados e compostados, respectivamente, na usina de triagem e compostagem.

Para elevados volumes de resíduos, recomenda-se a disposição em plataformas. Considerando uma altura máxima de $20 \mathrm{~m}$ de resíduos aterrados e solo, foi obtido o valor da área requerida com base nos valores de referência disponibilizados pela Associação Brasileira de Empresas de Limpeza Pública e Resíduos Especiais (ABRELPE, 2013): RSU coletado por habitante por dia $=0,810 \mathrm{~kg}$; densidade média dos resíduos compactados $=700 \mathrm{~kg} . \mathrm{m}^{-3}$.

Tabela 5 - Pesos ponderados dos fatores obtidos pela matriz WEIGHT.

\begin{tabular}{|c|c|c|c|}
\hline ID & $\begin{array}{l}\text { Nome do } \\
\text { arquivo fuzzy }\end{array}$ & Fator & $\begin{array}{l}\text { Pesos pon- } \\
\text { derados }\end{array}$ \\
\hline F1 & fuzzy_hidro & Fator distância de cursos d’água & 0,3154 \\
\hline F2 & fuzzy_svv & Fator distância das estradas vicinais & 0,1290 \\
\hline F3 & fuzzy_svp & $\begin{array}{l}\text { Fator distância de rodovias } \\
\text { principais }\end{array}$ & 0,0449 \\
\hline F4 & fuzzy_decliv & Fator declividade & 0,1290 \\
\hline F5 & fuzzy_npu & $\begin{array}{l}\text { Fator distância dos núcleos } \\
\text { populacionais urbanos }\end{array}$ & 0,0664 \\
\hline F6 & fuzzy_npr & $\begin{array}{l}\text { Fator distância dos núcleos } \\
\text { populacionais rurais }\end{array}$ & 0,3154 \\
\hline
\end{tabular}

ID: identificação

Tabela 4 - Fatores utilizados para a obtenção de cartas de adequabilidade e seus respectivos arquivos e pontos de controle.

\begin{tabular}{|c|c|c|c|c|c|c|c|}
\hline \multirow{2}{*}{ ID } & \multirow{2}{*}{ Fator } & \multicolumn{4}{|c|}{ Pontos de controle } & \multirow{2}{*}{ Função } & \multirow{2}{*}{ Referências } \\
\hline & & $A$ & B & C & D & & \\
\hline F1 & $\begin{array}{l}\text { Distância mínima de } 300 \\
\text { m da hidrografia }\end{array}$ & 300 & 700 & 700 & 700 & $\begin{array}{l}\text { Sigmoidal } \\
\text { crescente }\end{array}$ & $\begin{array}{c}\text { Samizava et al. (2008) } \\
\text { Gorsevski et al. (2012) } \\
\text { Marques (2001) } \\
\text { Melo (2001) }\end{array}$ \\
\hline F2 & $\begin{array}{l}\text { Distância mínima de } 100 \\
\text { m das estradas vicinais }\end{array}$ & 100 & 100 & 100 & 1.000 & $\begin{array}{c}\text { Linear } \\
\text { decrescente }\end{array}$ & Leite (2005) \\
\hline F4 & Declividade inferior a 30\% & 0 & 5 & 25 & 30 & Linear simétrica & Melo (2001) \\
\hline F5 & $\begin{array}{l}\text { Distância mínima de } \\
500 \text { m dos núcleos } \\
\text { populacionais urbanos }\end{array}$ & 500 & 2.000 & 8.000 & 10.000 & Linear simétrica & $\begin{array}{c}\text { Gorsevski et al. (2012) } \\
\text { Marques (2001) } \\
\text { Melo (2001) } \\
\text { NBR 13.896 (ABNT, 1997) }\end{array}$ \\
\hline
\end{tabular}

ID: identificação. 


\section{RESULTADOS E DISCUSSÃO}

\section{Análise multicritério: planos de informação de restrição}

$\mathrm{Na}$ Tabela 6, têm-se os percentuais referentes às áreas aptas e inaptas para cada critério de restrição, considerando toda a Zona da Mata. Nas Figuras 4 a 10, têm-se as áreas aptas e inaptas obtidas com base na metodologia descrita pela lógica booleana.

Observa-se que as restrições hidrografia, sistema viário e declividade apresentam extensas áreas inaptas com percentuais de 93,5; 27,9 e 14,3; respectivamente. Os resultados quanto aos critérios restritivos relacionados às questões naturais como hidrografia e declividade já eram esperados, devido às conhecidas características ambientais da mesorregião da Zona da Mata mineira.

A restrição aeroportos, apesar de representar um percentual reduzido se comparada às restrições já citadas, causa um impacto local considerável para os municípios que possuem aeroportos dentro de seus limites, pois representam uma perda de área correspondente a $254 \mathrm{~km}^{2}$. Destaca-se que essa perda pode impactar mais de um município, pois, dependendo da localização do aeroporto, a circunferência de área referente ao raio de $9 \mathrm{~km}$ pode abranger outros municípios.

\section{Planos de informação finais: arranjos territoriais ótimos}

Os mapas contendo as áreas finais resultantes da análise multicritério, que atendem aos requisitos descritos na metodologia e que apresentam área igual ou maior ao valor requerido calculado para cada ATO, são apresentados a seguir, da Figura 10 a 20. Na Tabela 7, têm-se os valores de área necessários para receber o volume de resíduos gerado em cada ATO, para um período de 20 anos, bem como a quantidade

Tabela 6 - Percentual de áreas aptas e inaptas para cada restrição.

\begin{tabular}{c|c|c|c} 
ID & Restrição & $\begin{array}{c}\text { Areas aptas } \\
(\%)\end{array}$ & $\begin{array}{c}\text { Areas inaptas } \\
(\%)\end{array}$ \\
R1 & Hidrografia & 6,5 & 93,5 \\
\hline R2 & Sistema viário & 72,1 & 27,9 \\
\hline R3 & Declividade & 85,7 & 14,3 \\
\hline R4 & Núcleos populacionais & 93,7 & 6,3 \\
\hline R5 & APPs de topo de morro & 99,9 & 0,1 \\
\hline R6 & Aeroportos & 92,9 & 7,1 \\
\hline R7 & Unidades de conservação & 98,6 & 1,5 \\
\hline R8 & Limite ATO & - & - \\
\hline
\end{tabular}

ID: identificação; APP: área de proteção permanente; ATO: arranjo territorial ótimo.

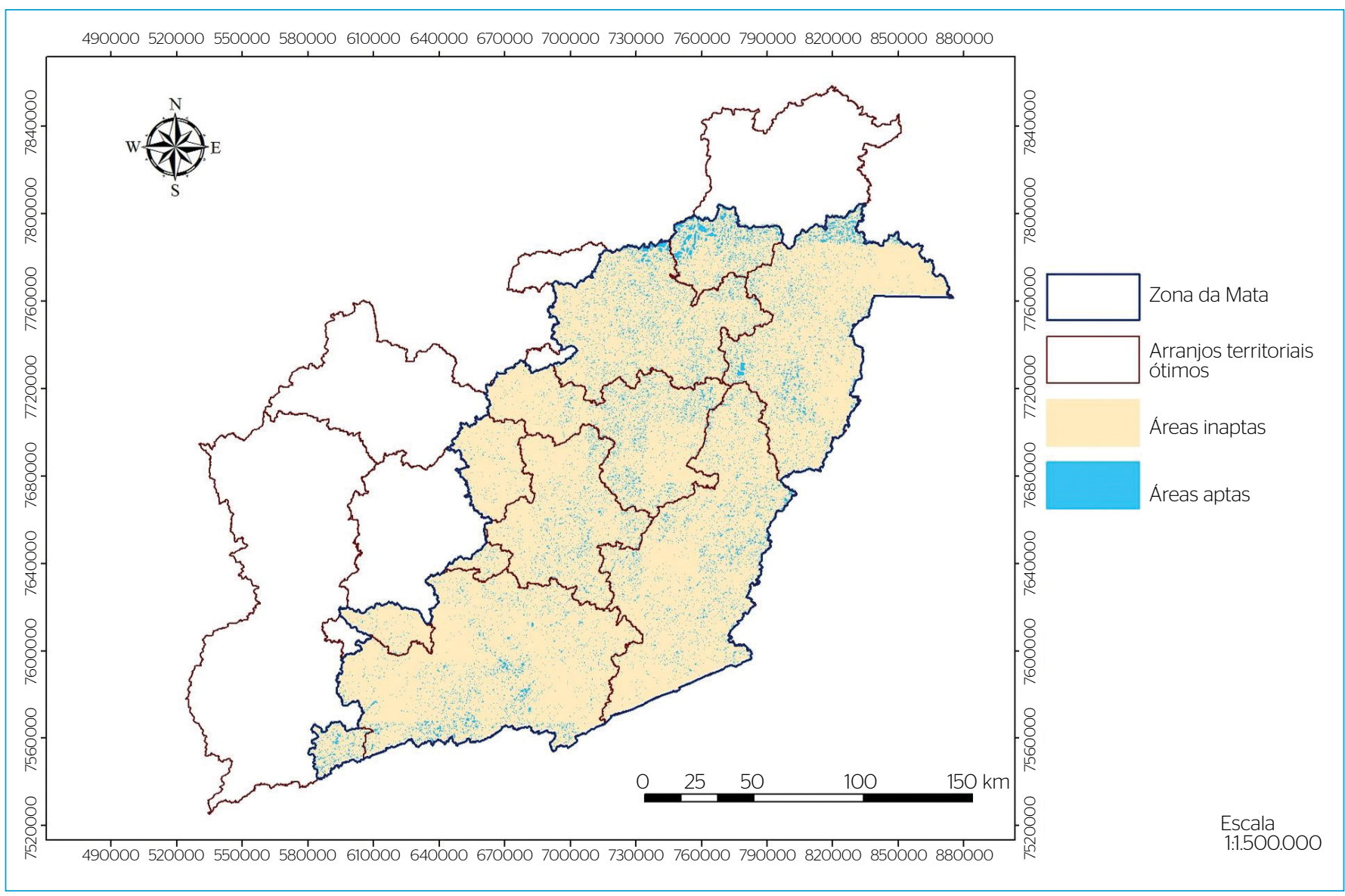

Figura 4 - Áreas aptas e inaptas para a restrição R1 - hidrografia. 


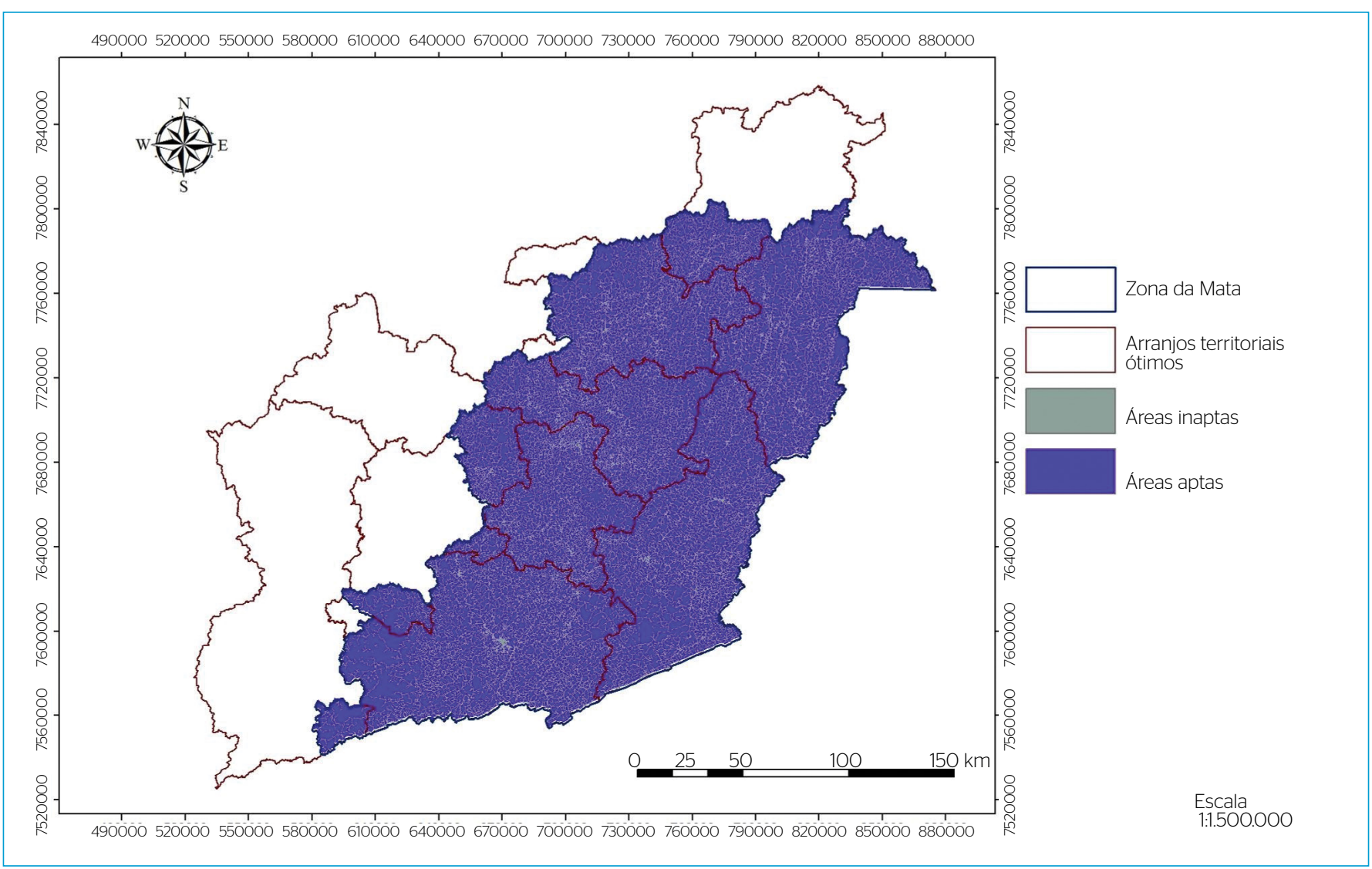

Figura 5 - Áreas aptas e inaptas para a restrição R - sistema viário.

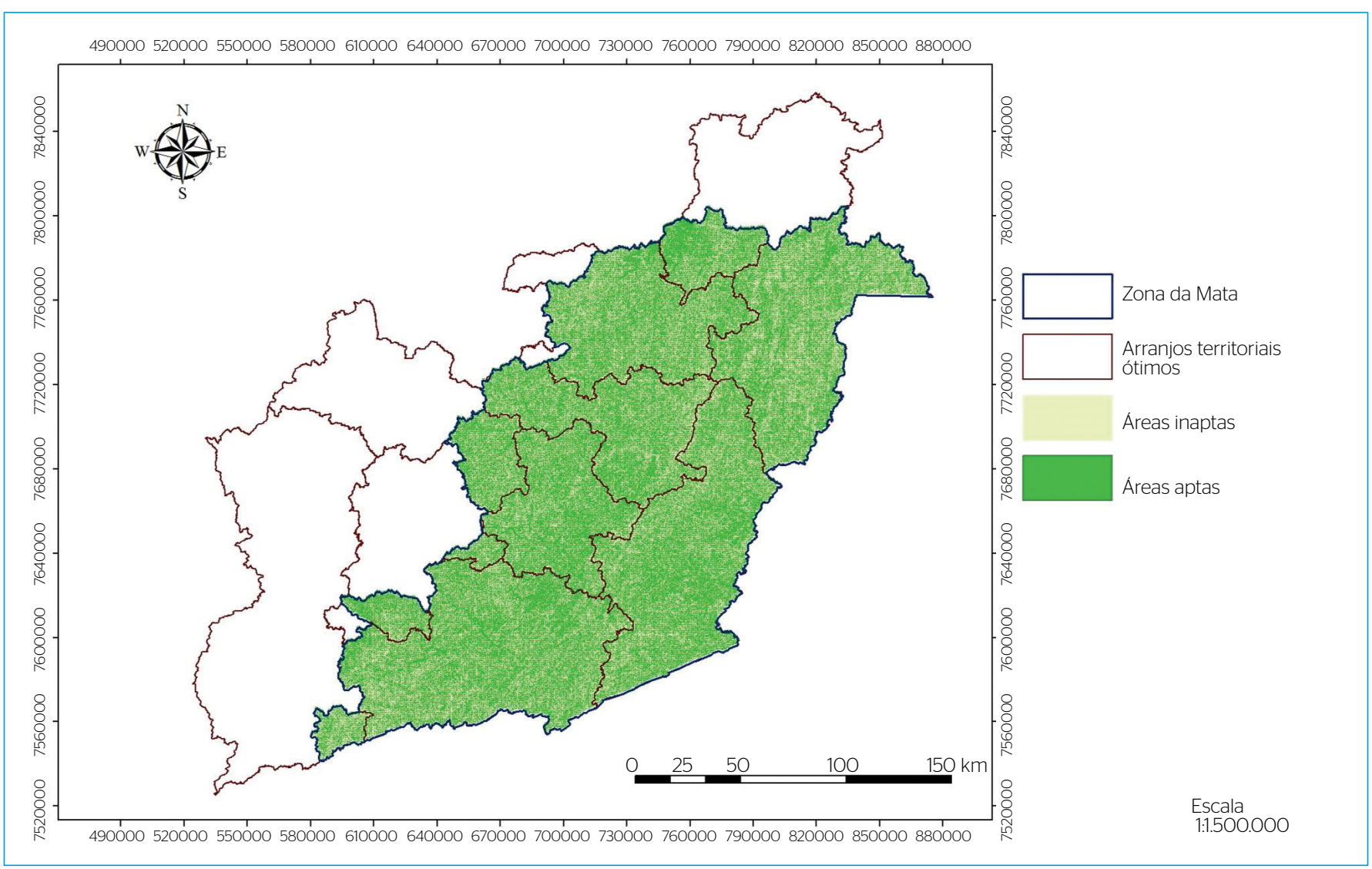

Figura 6 - Áreas aptas e inaptas para a restrição R3 - declividade. 


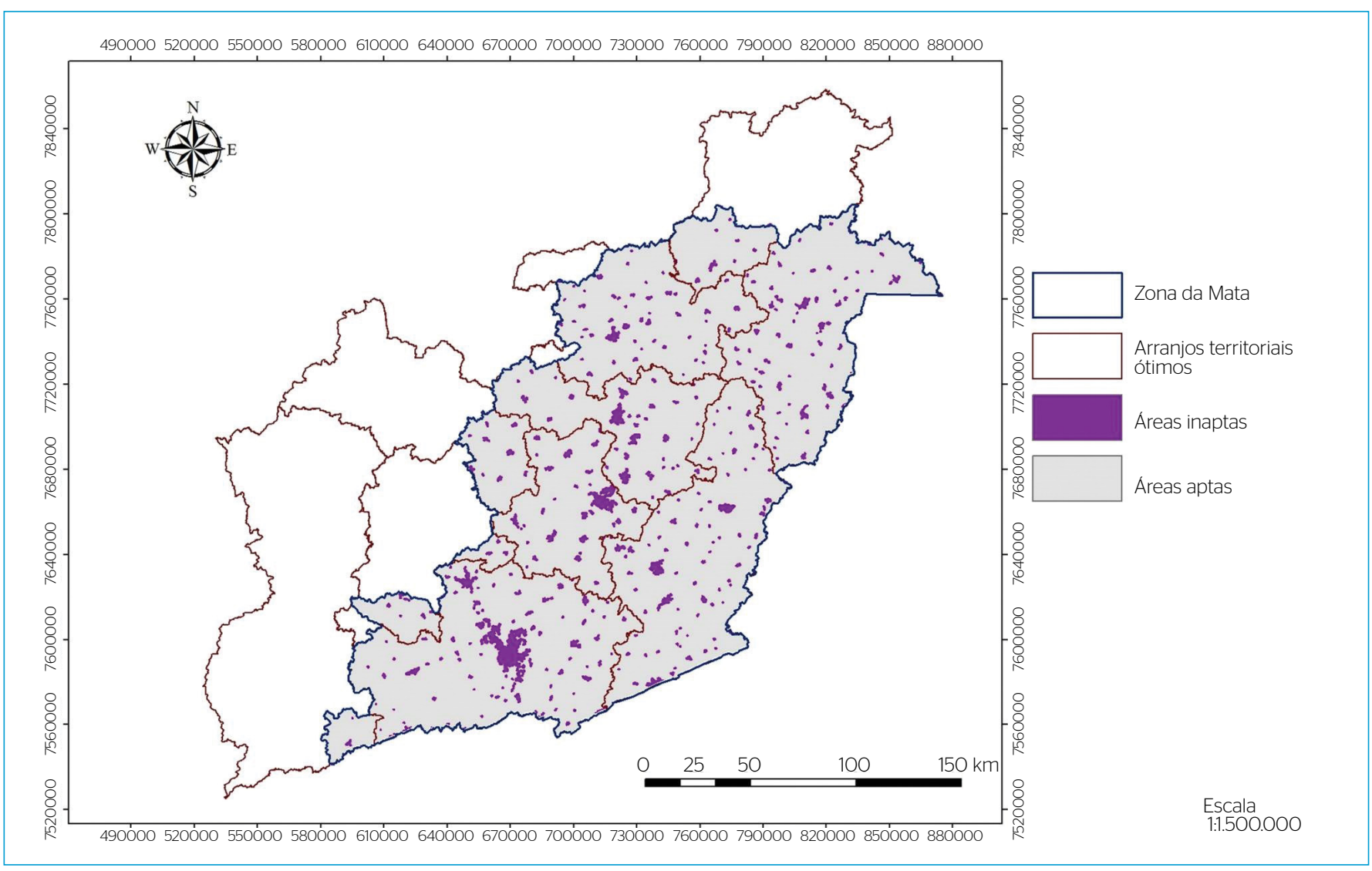

Figura 7 - Áreas aptas e inaptas para a restrição R4 - núcleos populacionais.

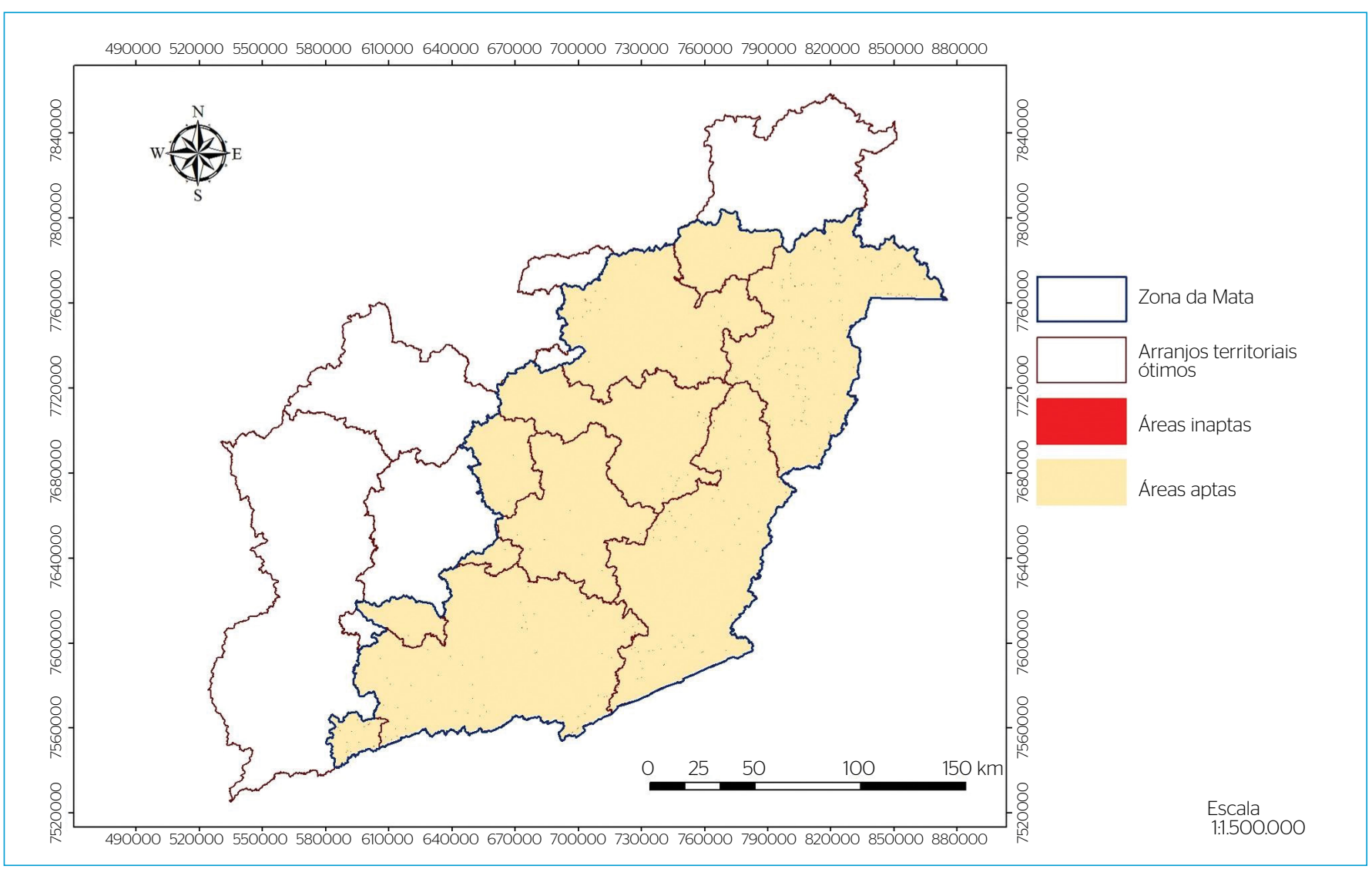

Figura 8 - Áreas aptas e inaptas para a restrição R5 - áreas de topo de morro. 


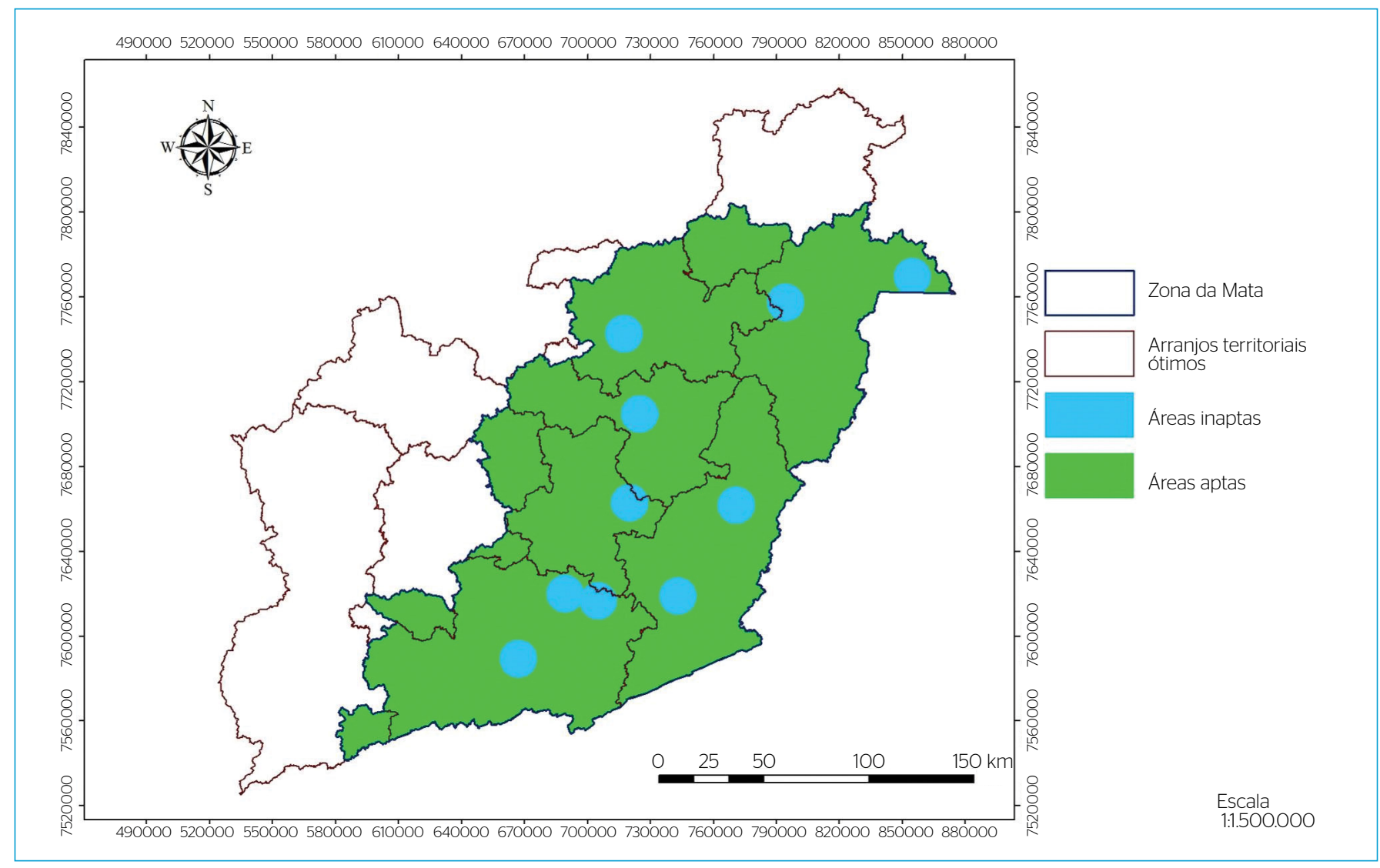

Figura 9 - Áreas aptas e inaptas para a restrição R6 - aeroportos.

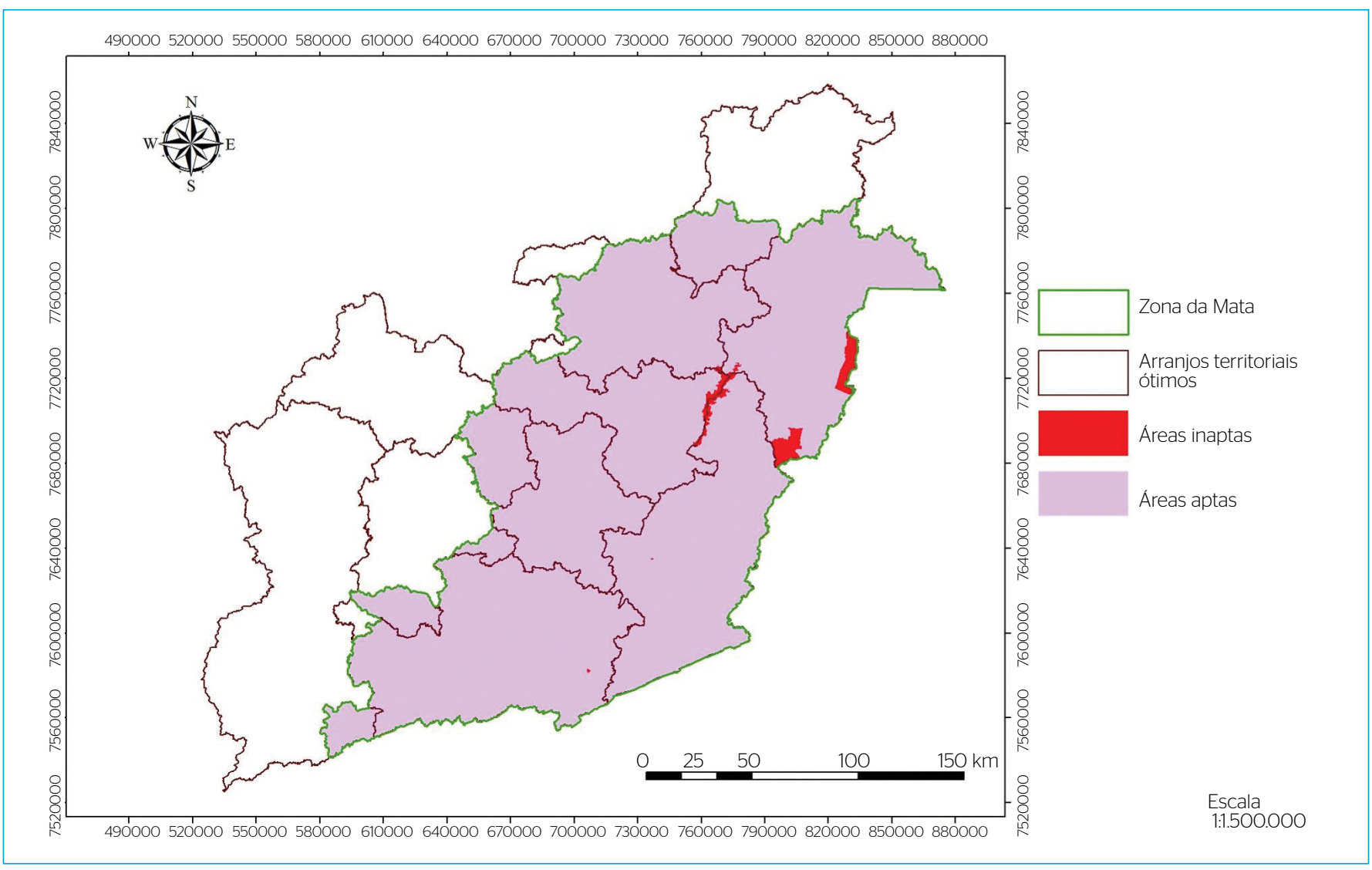

Figura 10 - Áreas aptas e inaptas para a restrição R7 - unidades de conservação. 
de áreas obtidas para cada ATO. As áreas obtidas não foram restritas quanto à adequabilidade.

Cabe ressaltar que os ATOs 4, 5, 10 e 15 não estão inteiramente inseridos na Zona da Mata (ver Figura 2). Sendo assim, foi considerada, no cálculo da geração de resíduos, apenas a população dos municípios

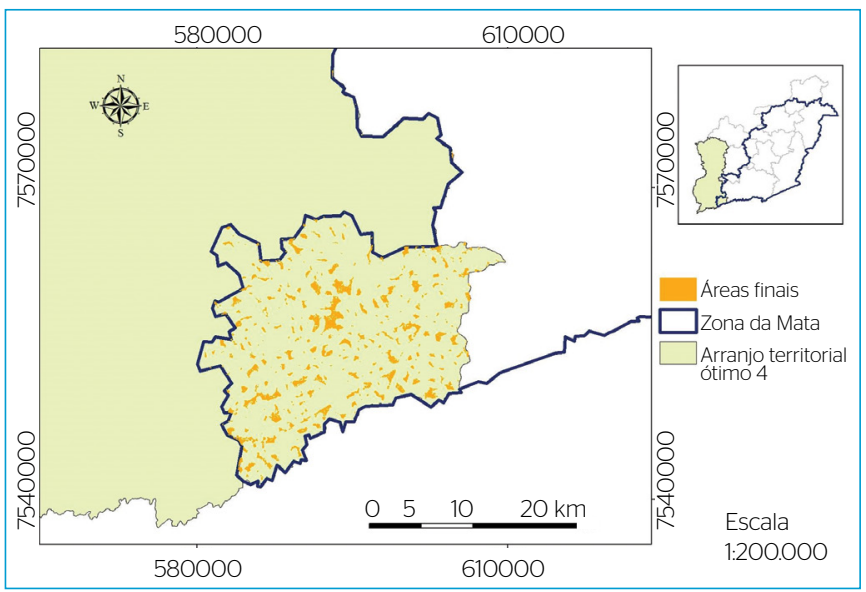

Figura 11 - Áreas finais ATO 4.

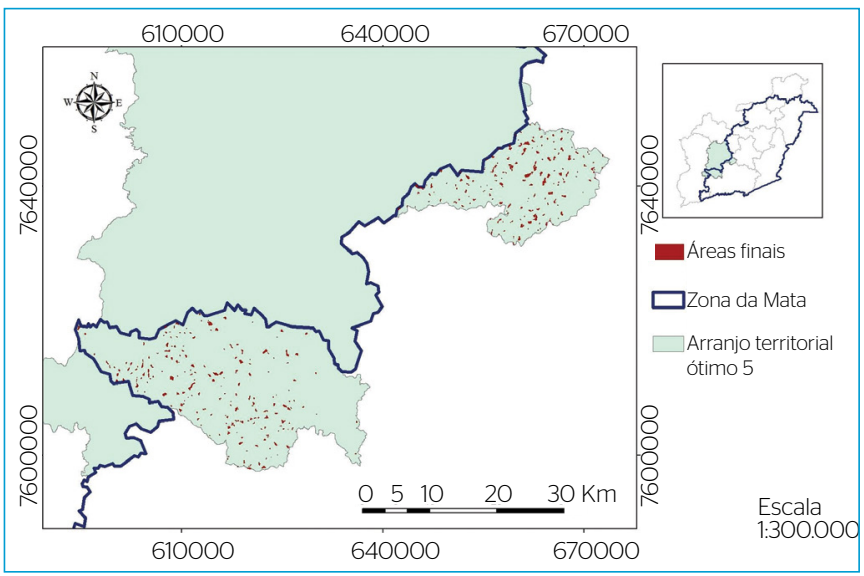

Figura 12 - Áreas finais ATO 5.

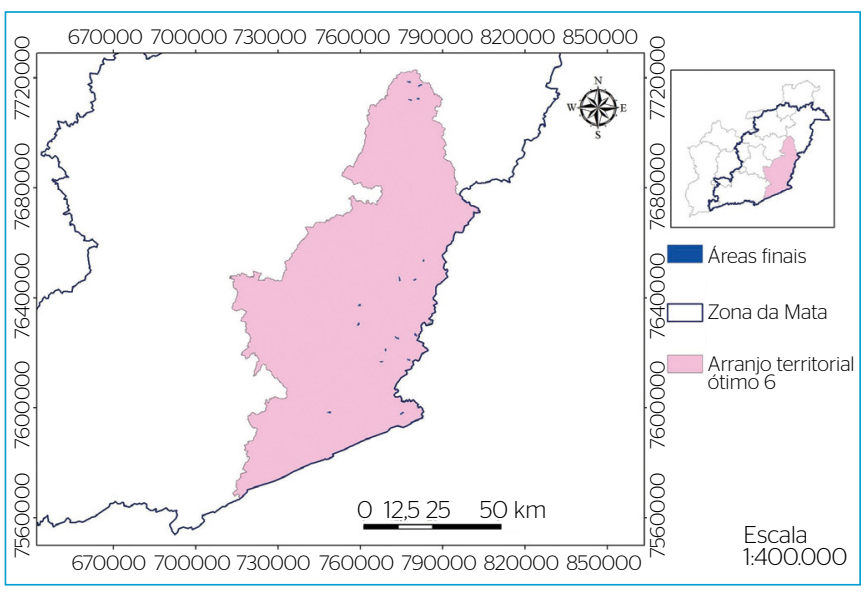

Figura 13 - Áreas finais ATO 6. pertencentes à mesorregião e, por isso, o valor de área requerida foi menor e resultou em um número de áreas finais bastante elevado, se comparado ao número de áreas obtidas para os ATOs totalmente inseridos na Zona da Mata (ATOs 6, 7, 12, 13, 45). No caso do ATO 4, por exemplo, apenas o município de Santa Rita de Jacutinga está inserido na Zona da Mata.

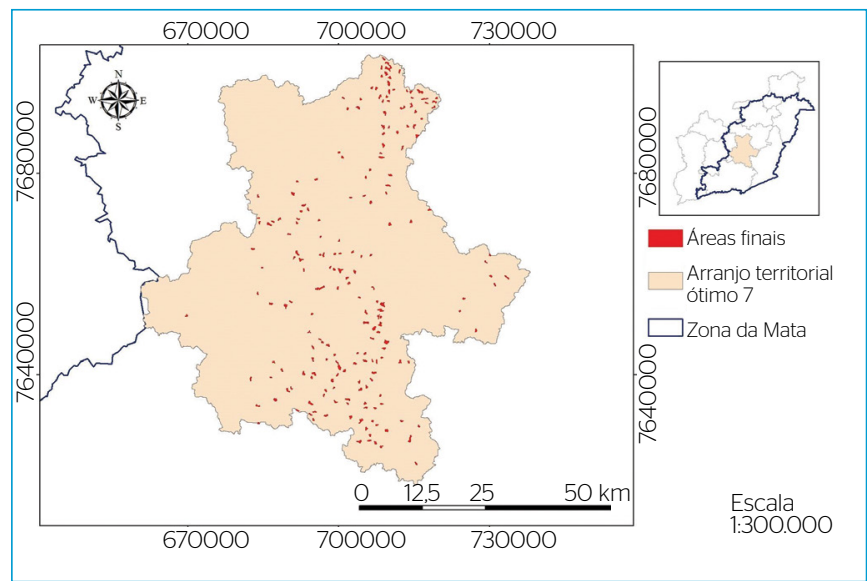

Figura 14 - Áreas finais ATO 7.

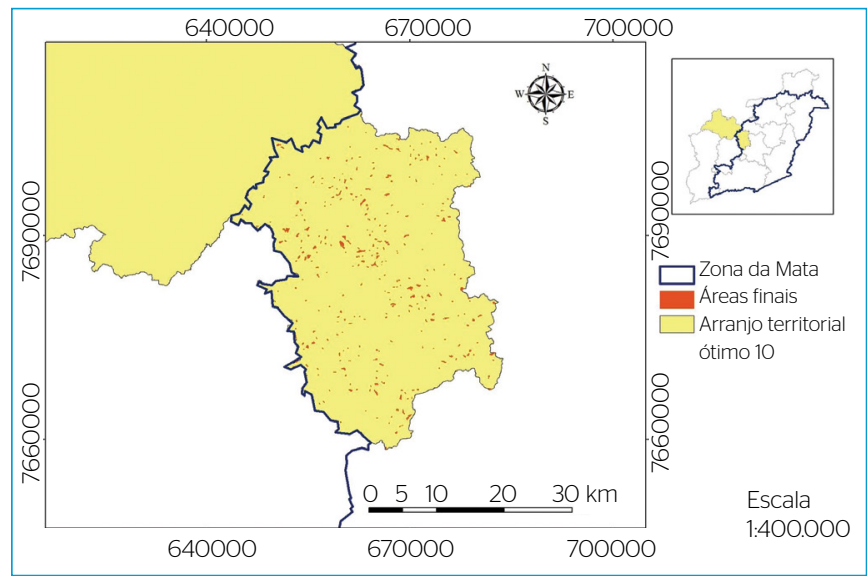

Figura 15 - Áreas finais ATO 10.

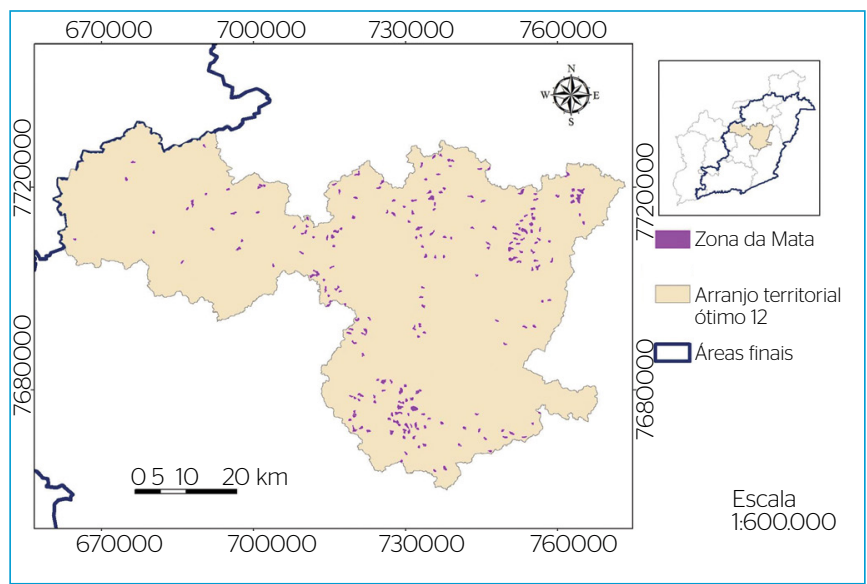

Figura 16 - Áreas finais ATO 12. 


\section{CONCLUSÕES}

O desenvolvimento de trabalhos com áreas de estudo muito extensas tem como principal dificuldade a obtenção de dados. Foi necessário um contato intensivo com órgãos públicos diversos e com outros docentes para a construção de uma base sólida para a realização das

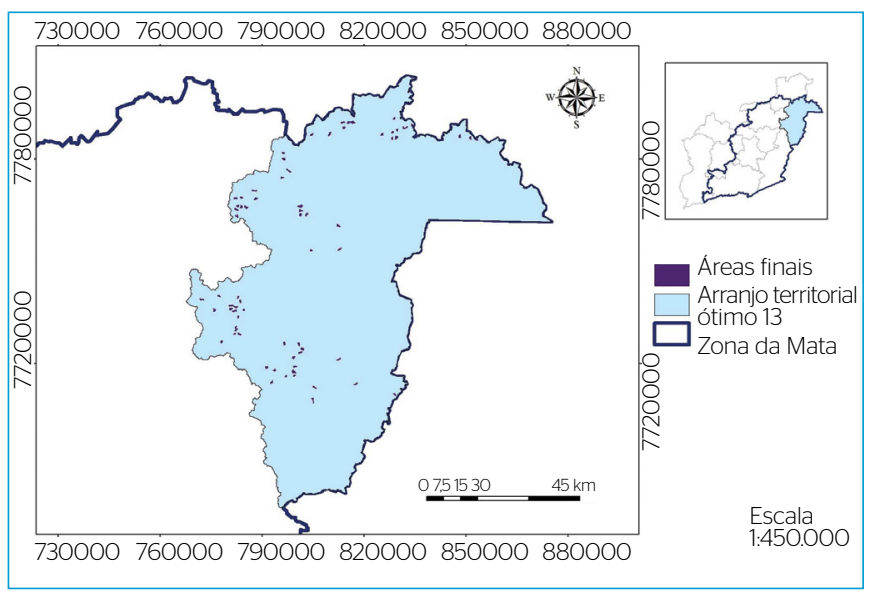

Figura 17 - Áreas finais ATO 13.

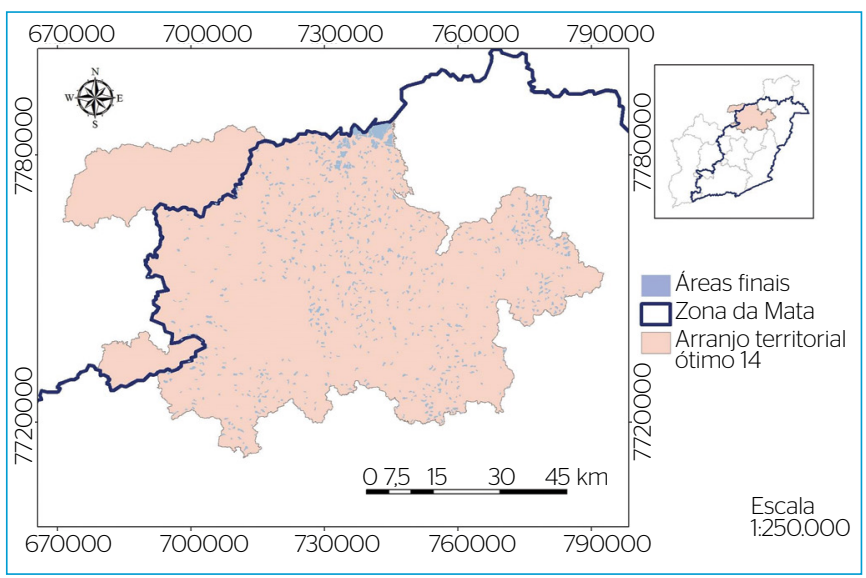

Figura 18 - Áreas finais ATO 14.

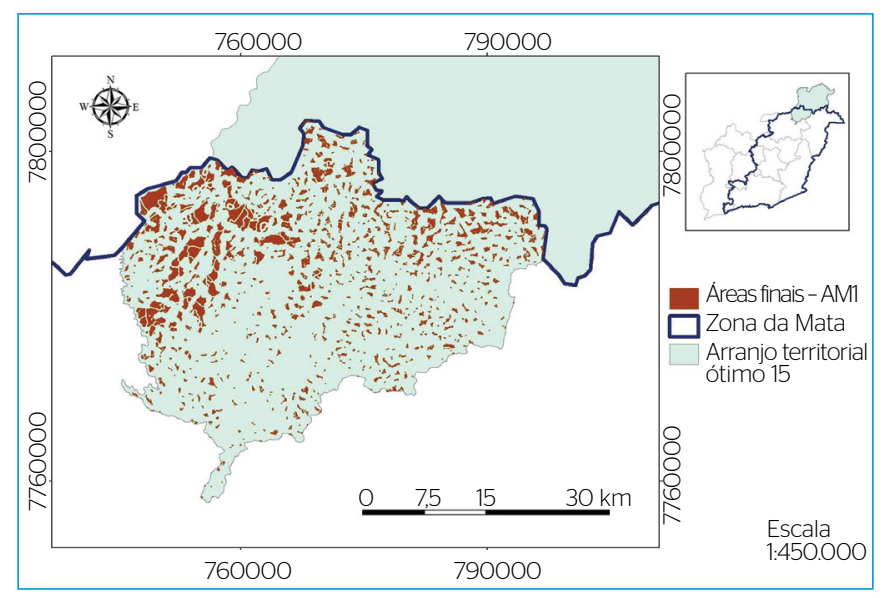

Figura 19 - Áreas finais ATO 15. análises espaciais. A obtenção, edição e adequação dos dados demandaram grande parte do tempo necessário para a conclusão do estudo.

Acerca dos resultados obtidos nas análises, verificou-se que a construção de um aterro sanitário e uma usina de triagem e compostagem para cada ATO implica na seleção de áreas bastante extensas cuja disponibilidade, na Zona da Mata é restrita, devido às características físicas limitantes.

Os resultados obtidos para os ATOs que não estão inteiramente inseridos dentro do limite da Zona da Mata apresentaram um grande número de áreas para a construção de aterros sanitários. Entretanto, esse número não representa a necessidade do ATO, pois a área mínima requerida não atende a todos os municípios do agrupamento, apenas os municípios que fazem parte da Zona da Mata. Sendo assim, as análises mais representativas foram para os ATOs que estão totalmente ou com grande parte de sua área inserida na Zona da Mata. São eles: ATOs 6, 7, 12, 13, 14 e 45.

É importante destacar que o estudo representa uma identificação preliminar de áreas para a construção de aterros sanitários. As áreas selecionadas como aptas podem apresentar outras características que

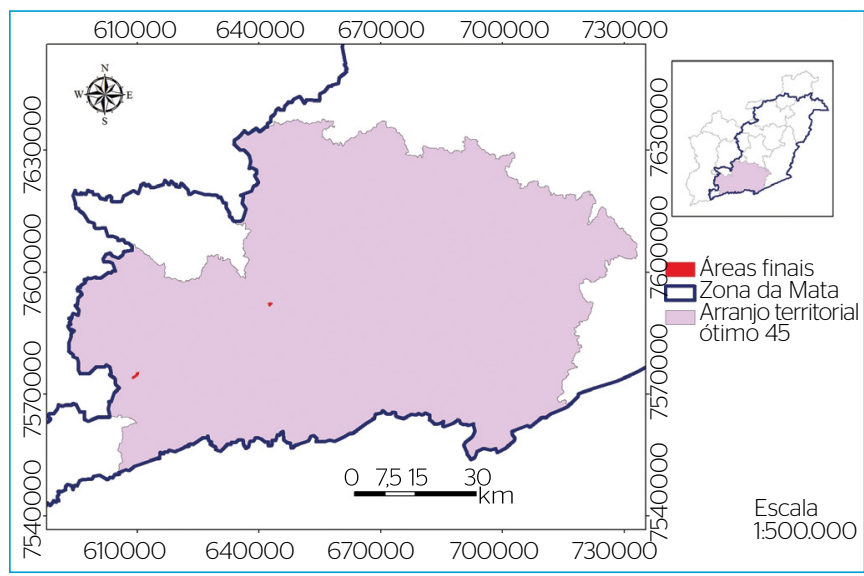

Figura 20 - Áreas finais ATO 45.

Tabela 7 - Áreas mínimas requeridas calculadas por arranjo territorial ótimo.

\begin{tabular}{c|c|c|c} 
ATO & $\begin{array}{c}\text { Area mínima requeri- } \\
\text { da (ha) }\end{array}$ & $\begin{array}{c}\text { Número de áreas } \\
\text { encontradas }\end{array}$ & $\begin{array}{c}\text { Faixa de adequabi- } \\
\text { lidade }\end{array}$ \\
\hline 4 & 0,06 & 4.242 & $16-239$ \\
\hline 5 & 0,20 & 815 & $57-235$ \\
\hline 6 & 15,80 & 16 & $45-226$ \\
\hline 7 & 4,80 & 210 & $40-250$ \\
\hline 10 & 0,45 & 465 & $33-218$ \\
\hline 12 & 5,70 & 219 & $33-242$ \\
\hline 13 & 12,70 & 68 & $30-240$ \\
\hline 14 & 2,70 & 975 & $26-253$ \\
\hline 15 & 0,50 & 2.408 & $32-239$ \\
\hline 45 & 35,70 & 2 & $81-255$ \\
\hline
\end{tabular}

ATO: arranjo territorial ótimo. 
podem inviabilizar a sua utilização para a disposição de resíduos, como dificuldade de acesso, presença de mata nativa, uso e ocupação do solo, além do fluxo de água subterrânea e permeabilidade do solo, que devem ser analisados (validados) in situ. Tais características podem reduzir o número de áreas obtidas.

Além disso, nessa análise não foi estabelecido um valor mínimo de adequabilidade para a seleção de áreas, assim, a restrição quanto a essa questão também poderia reduzir ainda mais o seu número.

O reduzido número de áreas obtidas para os ATOs representa um impasse na realização de consórcios intermunicipais que atendam esses arranjos territoriais considerando as normas legais vigentes. Além disso, os custos com o transporte dos resíduos, principalmente para municípios menores, pode inviabilizar a realização de um consórcio em tal escala.

\section{AGRADECIMENTOS}

Os autores gostariam de agradecer à Fundação Estadual do Meio Ambiente (FEAM) pelo apoio financeiro para a realização da pesquisa e à Coordenação de Aperfeiçoamento de Pessoal de Nível Superior pela bolsa de estudos.

\section{REFERÊNCIAS}

ABRELPE - ASSOCIAÇÃO BRASILEIRA DAS EMPRESAS DE LIMPEZA PÚBLICA E RESÍDUOS ESPECIAIS. (2013) Panorama de resíduos sólidos no Brasil. São Paulo: ABRELPE. Disponível em: <http://www.abrelpe.org. br/Panorama/panorama2O13.pdf>. Acesso em: O2 dez. 2014.

ABNT - ASSOCIAÇÃO BRASILEIRA DE NORMAS TÉCNICAS (1997). NBR 13.896: aterros de resíduos não perigosos - critérios para projeto, implantação e operação. Rio de Janeiro: ABNT.

BRASIL. (2000) Lei no 9.985, de 18 de julho de 2000. Regulamenta o art. 225, § 10, incisos I, II, III e VII da Constituição Federal, institui o Sistema Nacional de Unidades de Conservação da Natureza e dá outras providências. Brasília: Diário Oficial da União.

BRASIL. (2010) Lei no 12.305, de 2 de agosto de 2010. Institui a Política Nacional de Resíduos Sólidos; altera a Lei no 9.605, de 12 de fevereiro de 1998; e dá outras providências. Brasília: Diário Oficial da União.

BRASIL. (2011) Ministério da Defesa. Comando da Aeronáutica. Portaria no 249/GCS/2011, de 06 de maio de 2011. Aprova a edição do PCA 3-2, que dispõe sobre o Plano Básico de Gerenciamento do Risco Aviário PBGRA nos aeródromos brasileiros. Disponível em: <http://www.cenipa. aer.mil.br/cenipa/Anexos/article/205/PCA_3-2_PBGRA.pdf>. Acesso em: 15 jul. 2014

BRASIL. (2012) Lei no 12.651, de 25 de maio de 2012. Dispõe sobre a proteção da vegetação nativa; altera as Leis nos 6.938 , de 31 de agosto de 1981, 9.393, de 19 de dezembro de 1996, e 11.428, de 22 de dezembro de 2006; revoga as Leis nos 4.771, de 15 de setembro de 1965, e 7.754, de 14 de abril de 1989, e a Medida Provisória no 2.166-67, de 24 de agosto de 2001; e dá outras providências. Brasília: Diário Oficial da União.

BRASIL. (2014) Ministério do Meio Ambiente. Secretaria de Biodiversidade e Florestas. Cadastro nacional de unidades de conservação: dados consolidados. Brasília: MMA. Disponível em: <http://www.mma.gov.br/areas-protegidas/cadastro-nacional-de-ucs/ dados-consolidados>. Acesso em: 10 set. 2014.
COPAM - CONSELHO ESTADUAL DE POLITICA AMBIENTAL DE MINAS GERAIS. (2008) Deliberação Normativa no 118, de 27 de junho de 2008. Altera os artigos $2^{\circ}, 3^{\circ}$ e $4^{\circ}$ da Deliberação Normativa 52/2001, estabelece novas diretrizes para adequação da disposição final de resíduos sólidos urbanos no Estado, e dá outras providências. Belo Horizonte: Diário Executivo.

FEAM - FUNDAÇÃO ESTADUAL DO MEIO AMBIENTE. (2014) Gestão Integrada de Resíduos Sólidos Urbanos. Disponivel em: <http://www. feam.br/minas-sem-lixoes/gestao-compartilhada-de-sru $\geq$. Acesso em: 01 mai. 2014

GORSEVSKI, P.V.; DONEVSKA, K.R.; MITROVSKI, C.D.; FRIZADO, J.P. (2012) Integrating multi-criteria evaluation techniques with geographic information systems for landfill site selection: a case study using ordered weighted average. Waste Management, v.32, n.2, p.287-296.

IBGE - INSTITUTO BRASILEIRO DE GEOGRAFIA E ESTATISTICA. (2012a) Cidades. Disponível em: <http://cidades.ibge.gov.br/xtras/home.php> Acesso em: 13 dez. 2012.

IBGE - INSTITUTO BRASILEIRO DE GEOGRAFIA E ESTATÍSTICA. (2012b). Cartas Topográficas vetoriais do mapeamento sistemático (escalas: 1:50.000 e 1:100.000). Disponível em: <http://ibge.gov.br/ home/geociencias/download/arquivos/index1.shtm>. Acesso em: 10 nov. 2012

LEITE, N.B.F. (2005) Associação da Análise Booleana e Lógica Fuzzy ao sistema de informação geográfica aplicados a Planos Diretores. Estudo de caso: Ponte Nova, MG. Dissertação (Mestrado) - Universidade Federal de Viçosa, Viçosa.

MARQUES, E.T. (2001) Identificação de áreas potenciais para a disposição de resíduos de mármores e granitos em Cachoeiro de Itapemirim - ES. Dissertação (Mestrado). Universidade Federal de Viçosa, Viçosa. 
MELO, A.L.O. (2001) Avaliação e seleção de áreas para implantação de aterro sanitário utilizando Lógica Fuzzy e Análise Multicritério: uma proposta metodológica. Aplicação ao municipio de Cachoeiro de Itapemirim- ES. Dissertação (Mestrado) - Universidade Federal de Viçosa, Viçosa.

OLIVEIRA, G.C. \& FERNANDES FILHO, E.I. (2013) Metodologia para delimitação de APPs em topos de morros segundo o novo Código Florestal brasileiro utilizando sistemas de informação geográfica. In: Simpósio Brasileiro de Sensoriamento Remoto (SBSR), 16 Anais... São José dos Campos: INPE.

SAATY, T.L. (1990) Decision making for Leaders. Pittsburgh: RWS Publications.
SAMIZAVA, T.M.; KAIDA, R.H.; IMAI, N.N.; NUNES, J.O.R. (2008) SIG aplicado à escolha de áreas potenciais para instalação de aterros sanitários no município de Presidente Prudente - SP. Revista Brasileira de Cartografia, v.60, n.1, p.43-55.

VOOGD, H. (1983). Multicriteria evaluation for urban and regional planning. London: Pion Ltd.

WEBER, E. \& HASENACK, H. (2000) Avaliação de áreas para instalação de aterro sanitário através de análises em SIG com classificação contínua dos dados. Porto Alegre: UFRS, 2000.

ZADEH, L.A. (1965) Fuzzy sets. Information and control, v.8 p.338-353. 